\title{
Desplegando el Estado: los ejércitos republicanos en las provincias del Cauca, 1832-1855*
}

\section{Luis Ervin Prado Arellano}

\begin{abstract}
Profesor titular del Departamento de Historia de la Universidad del Cauca (Colombia). Correo electrónico: leprado@unicauca.edu.co o luisprad30@yahoo.es. Licenciado en Historia de la Universidad del Valle (Colombia), Magíster en Historia de la Universidad Industrial de Santander y candidato a Doctor en Historia Latinoamericana de la Universidad Andina Simón Bolívar (Ecuador). Recientemente ha publicado, entre otros, "Los avatares de la educación militar en la Nueva Granada (1820-1855)", en Historia y Memoria N ${ }^{\circ}$ 17, (2018); "Escuelas en la tormenta parroquial: conflicto y disputa local en la provincia de Popayán en el Estado de la Nueva Granada, 1833-851” en Historelo, Revista de Historia Regional y Local Vol. 10, (2018) y “La Paz Conservadora, 1841-1849”, en Paz en la República. Colombia siglo XIX, libro editado por Margarita Garrido Payán, Carlos Camacho Arango, Daniel Gutiérrez Ardila, (2019). Sus líneas de investigación incluyen la construcción del Estado-Nación y las fuerzas armadas en el siglo XIX.
\end{abstract}

Recibido: 28 de marzo de 2019

Aprobado: 8 de mayo de 2019

Modificado: 22 de mayo de 2019

Artículo de investigación científica

DOI: http://dx.doi.org/10.15648/hc.35.2019.6

Este artículo forma parte del proyecto 4994 inscrito en la Vicerrectoría de Investigaciones de la Universidad del Cauca y del trabajo doctoral en Historia Latinoamericana que ha contado con el apoyo de una beca y una comisión de estudios otorgada por la Universidad Andina Simón Bolívar (Ecuador) y la Vicerrectoría Académica de la Universidad del Cauca (Colombia), respectivamente. Esta publicación está bajo una licencia Creative Commons Reconocimiento-NoComercial 4.0 
Desplegando el Estado: los ejércitos republicanos en las provincias del Cauca, 1832-1855

\title{
Resumen
}

Los recientes estudios sobre los ejércitos republicanos en el siglo XIX han señalado su relevancia en la construcción de los procesos de estatalidad y estatalización. El presente artículo explora esta línea investigativa, identificando las tareas que el ejército permanente y la guardia nacional desempeñaron en las provincias del Cauca entre los años treinta y cincuenta del siglo XIX, las cuales permitieron hacer más tangible el Estado a los hombres y mujeres que habitaron la región, tanto en las principales ciudades como en las localidades más alejadas de los centros de poder político.

Palabras clave: Estado, Estatalidad (niveles de gobierno), estatalización, ejércitos republicanos.

Deploying statehood: the republican armies in the province of Cauca, 1832-1855

\begin{abstract}
Recent studies about the 19th century republican forces indicate the importance of their role in the progress towards statehood. This article explores further along the line of said research. It identifies the tasks realized by the standing army and the national guard in the provinces of Cauca in the 1830s through the 1850s. Those activities allowed the notion of State to become more tangible to the men and women inhabiting the region, both in the principal cities and the remote localities distant from political central power.
\end{abstract}

Keywords: State, Statehood (levels of government), State-formation, Republican Armies.

Implantação do Estado: os exércitos republicanos nas províncias de Cauca, 1832-1855

\section{Resumo}

Os estudos recentes sobre os exércitos republicanos no século XIX apontaram sua relevância na construção dos processos de estado. Este artigo explora esta linha de pesquisa, identificando as tarefas que o exército permanente e a guarda nacional realizaram nas províncias de Cauca durante os anos 30 e 50 do século XIX, as quais permitiram 
tornar o estado mais tangível aos homens e mulheres que habitaram a região, tanto nas principais cidades quanto nas cidades mais distantes dos centros de poder político.

Palavras-chave: Estado, níveis de governo, nacionalização, exércitos republicanos.

\section{Déploiement de l'État: les armées républicaines dans les provinces du département de Cauca, 1832-1855}

\section{Résumé}

Les études les plus récentes sur les armées républicaines dans le XIX siècle ont remarqué leur importance dans la construction de processus d'étatisme et d'étatisation. Cet article exploite cette ligne de recherche en repérant les tâches que l'armée permanente et la police nationale exercèrent dans les villages du Cauca entre les années trente et les années cinquante du XIX siècle, lesquelles permirent de faire plus tangible 1'”Etat, aux hommes et femmes qui habitèrent dans la région, tant dans les grandes villes que dans les villages plus éloignés des centres du pouvoir politique.

Mots clés: État, étatisme (niveaux du gouvernement) étatisation, armées républicaines

\section{INTRODUCCIÓN}

En el informe presentado por el secretario de Guerra al Congreso de la Nueva Granada en 1851, el oficial, para demostrar el alto grado de legitimidad que en ese momento contaban las fuerzas armadas, señaló cómo los gobernadores solicitaban la permanencia de unidades militares en sus respectivos territorios. Al respecto escribió:

... En otro tiempo se miraba como una calamidad para un pueblo que se acantonase en el algún cuerpo de tropas, y hoy por muchas provincias se reclama se les den guarniciones o se aumenten las que tienen [...]. El poder ejecutivo se ha negado a las exigencias de aquellas gobernaciones porque desea que todos los pueblos se acostumbren a obedecer y respetar las autoridades, sin que sea necesario el aparato de la fuerza armada... ${ }^{1}$.

1 Informe del secretario de Estado en el despacho de Guerra de la Nueva Granada al Congreso cons- 
¿Cuál era la razón para que las primeras autoridades políticas de la provincia solicitaran la presencia permanente de cuerpos armados en sus jurisdicciones? Parte de la respuesta se hallaba en sus labores desempeñadas en los sitios donde se acantonaban. Algunas de ellas fueron las funciones de policía y control social que prestaron a los funcionarios provinciales, en un período en el que, a pesar de los informes y conveniencias, nunca se organizó un cuerpo de gendarmería en el país que ayudara a vigilar los caminos y perseguir partidas de salteadores, contrabandistas o prófugos de la ley, por los costos operativos ${ }^{2}$. En general, estas actividades quedaron en manos de las compañías de guardia nacional o de compañías o piquetes del ejército regular.

Lo señalado arriba nos introduce en un rico campo de estudios que en las últimas décadas viene promoviendo la disciplina histórica, en torno a la construcción del Estado. Dicho tema promovió un interés por las fuerzas armadas, que aún en la década del ochenta del siglo XX estaba sujeto a un problema modelado por la academia anglosajona sobre las relaciones civiles-militares, para explicar las razones por las cuales los hombres en armas obstaculizaron los procesos democráticos del continente ${ }^{3}$. El nuevo

titucional de 1851. Bogotá, Imprenta del Neo-Granadino, por León Echevarría, (1851), 4-5.

2 A pesar de los esfuerzos de los países hispanoamericanos de constituir cuerpos de policía, en general estos se vieron postergados en las primeras décadas de vida independiente a pesar de la urgente necesidad de ejercer control social en las áreas rurales poco después de concluidas las guerras de independencia. Es solo hacia la segunda mitad del siglo XIX en que se dieron algunas experiencias exitosas. Para el caso mexicano véase: Paul J. Vanderwood, Los rurales mexicanos (México: Fondo de Cultura Económica, 2012).

3 Amos Perlmutter, "The Praetorian State and the Praetorian Army: Toward a Taxonomy of Civil-MilitaryRelations in Developing Polities", Comparative Politics, Vol. 1, No. 3 (1969), 382-404; Frederick M. Nunn, "Latin American Military-Civilian from independence to the present. A course conspectus", History teacher, Vol. 14, No 3 (1981), 423-437. El principal estudio: Brian Loveman, For la Patria. Politics and the Armed Forces in Latin American (Wilmington: Scholary Resources Inc, 1999). Un balance para el caso argentino: Germán Soprano, "La profesión militar en los estudios sobre fuerzas armadas y sociedad. Lecturas, interpretaciones, y usos desde la argentina actual", Cuadernos de Marte, Vol. 4, No. 5 (2013), 63-97. En Colombia, tal vez el único trabajo existente de este programa investigativo en el siglo XIX es el de Anthony P. Maingot, "Social structure, social status and civil-military conflicto in urban Colombia, 1810-1851", Nineteenth Century Cities. Essays in the new urban History, Stephan Thernstrom, Richard Sennett, Eds. (New Haven: Yale University Press, 1969), 296-355. 
enfoque se desmarcó de aquella línea heurística, y le apuntó a estudiar la forma como el ejército y las milicias ayudaron a construir Estado, la ciudadanía e imaginar la nación ${ }^{4}$.

Bajo esta nueva perspectiva se revalorizaron las fuerzas armadas, al identificar su función protagónica en los procesos de construcción de la estatalidad y estatalización ${ }^{5}$. La primera se entiende como el proceso por medio del cual el Estado hace presencia en los diversos niveles jurisdiccionales de su territorio y ejerce formalmente la soberanía; la segunda se refiere a la capacidad de modelar la vida de las localidades a partir de introducir diversas instituciones (justicia, hacienda, policía, etc.), las cuales encarnan una ideología moralizadora, disciplinadora y generadora de una identidad colectiva; de ahí que algunos autores consideren al Estado una revolución cultural ${ }^{6}$.

4 Una síntesis de esta tesis en: Miguel Ángel Centeno, Sangre y Deuda. Ciudades, Estado y construcción de nación en América Latina (Bogotá: Universidad Nacional, 2014). También véase: Juan Carlos Garavaglia "Ejército y milicia: Los campesinos bonaerenses y el peso de las exigencias militares, 1810-1860”, Anuario IEHS, No 18 (2003), 153-187; Flavia Macías, "El deber de enrolarse y el derecho a votar: reflexiones en torno a la ciudadanía armada y el sufragio en Argentina, 1863-1877”, Revista de Indias, Vol. 76, No. 266, (2016), 233-258; Flavia Macías, "Milicias, levantamientos armados y construcción republicana en Hispanoamérica. Estudios y propuestas para el siglo XIX”, Boletín del Instituto de Historia de Argentina “Dr. Emilio Ravignani”, No 42 (2015), 24-30; Flavia Macías, Armas y Política en Argentina. Tucumán, siglo XIX (Madrid: Consejo Superior de Investigaciones Científicas, 2014); Flavia Macías e Hilda Sabato. "La Guardia Nacional: Estado, política y uso de la fuerza en la Argentina de la segunda mitad del siglo XIX", Revista PolHis, Vol. 6, No 11 (2013), 7081. Para una reflexión en torno a la violencia y la construcción estatal: Marta Irurozqui, Ciudadanos armados de ley. A propósito de la violencia en Bolivia, 1830-1875 (La Paz: Instituto Francés de Estudios Andinos, Ediciones Plural, 2018); Carmen McEvoy, Alejandro Rabinovich, Eds. Tiempo de guerra. Estado, nación, y conflicto armado en el Perú, siglo XVII-XIX (Lima: Instituto de Estudios Peruano, 2018); Romana Falcón, Raymon Buve (coordinadores), Pueblos en tiempos de Guerra. La formación de la nación en México, Argentina y Brasil (1800-1920) (México: El Colegio de México, 2017).

5 Por estatalidad se entenderá a lo largo del texto el despliegue ejercido por el Estado en su territorio, a partir de la forma como construyó la estructura de encadenamiento del centro a la parroquia. Así, en la Nueva Granada se presentaron cuatro niveles de estatalidad en el período de estudio: nacional, provincial, cantonal y parroquial. La estatalidad es la presencia del Estado en un territorio donde ejerce una serie de funciones y prácticas que obedecen a una ideología moralizante. Consultar: Miriam Galante, Miriam, Marta Irurozqui Victoriano, María E. Argeri. La razón de la fuerza y el fomento del derecho. Conflictos jurisdiccionales, ciudadanía y mediación estatal (Tlaxcala, Bolivia y Norpatagonia) (Madrid: Consejo Superior de Investigaciones Científicas, 2011), 9-27; María E Argeri, De guerreros a delincuentes. La desarticulación de las jefaturas indígenas y el poder judicial.

6 Sobre el sentido de revolución cultural: Philip Corrigan y Derek Sayer, "El Gran Arco. La formación 
Lo señalado no significa asumir que el Estado siempre impone su lógica, aunque es su pretensión, pues siempre se enfrenta con los mores locales, las inercias administrativas y las negociaciones implícitas o explicitas que entre funcionarios y habitantes se suscitan en torno a las leyes. Dicha afirmación es más evidente en las primeras décadas del siglo XIX latinoamericano, donde el nivel de autonomía del Estado fue siempre precario, pues estuvo atrapado por los intereses privados, las redes de poder, entre otras. En resumen, como lo argumentan los hortelanos de la etnografía de Estado, sus políticas no son lineales, ya que en los contextos donde operó, se negociaba, se adaptaba, se torcía o se quebraba su imperio de la ley ${ }^{7}$.

El presente escrito señala la importancia que tuvieron las fuerzas armadas en las provincias del Cauca en el proceso de construcción de la estatalidad neogranadina. Para ello se enfocará en primer lugar, en describir brevemente la forma de organización del ejército y la guardia nacional de la Nueva Granada, a partir de la Carta fundamental de 1832, y las razones por las cuales el suroccidente se caracterizó por la presencia permanente de unidades armadas. En segundo lugar, se pasará a identificar las diversas actividades desempeñadas por las unidades acantonadas en la región, que ayudaron a hacer tangible al Estado aun en las comarcas más remotas del territorio, por medio del fortalecimiento a la justicia, la hacienda pública, entre otras tareas realizadas. Posteriormente, se analizará lo que comprometió dichas acciones en relación con la construcción de la estatalidad y estatalización del Estado entre los años treinta y los cincuenta del siglo XIX.

del estado inglés como revolución cultural", en María L. Lagos y Pamela Calla, Comps, Antropología de Estado. Dominación y prácticas contestarías en América Latina, (La Paz: INDH/PNUD, 2007), 39-116.

7 Como lo se ha señalado en el caso argentino (y no exime el neogranadino), la estatalidad era precaria, por lo tanto, su grado de autonomía bajo, poroso, traslapado con los intereses privados. Juan Carlos Garavaglia, La disputa por la construcción nacional Argentina. Buenos Aires, la Confederación y las provincias (1850-1865) (Buenos Aires: Prometeo Editores, 2015), 162-164. Sobre la noción de etnografía de Estado véase a: Veena Das y Deborah Poole, "El Estado en las márgenes. Etnografías comparadas", Cuadernos de Antropología Social, No. 27, (2008), 19-52; Cecilia Méndez, La República plebeya. Huanta y la formación del Estado peruano, 1820-1850 (Lima: Instituto de Estudios Peruanos, 2014), 245-293. 


\section{El Ejército republicano en las provincias del Cauca ${ }^{8}$}

El Ejército republicano de la Nueva Granada, formado a partir de la Constitución de 1832, fue organizado bajo los principios de una fuerza armada no deliberativa sujeta al dosel constitucional. En ese proceso sus unidades de combate terrestre fueron divididas en dos grandes componentes: el permanente y la guardia nacional auxiliar y la cívica, después denominada local. El primero era una fuerza regular, con vocación profesionalizante al estar sujetos sus miembros a las ordenanzas, a las cadenas de mando y la jerarquía militar; pero por la precariedad del fisco debió mantener un pie de fuerza reducido, insuficiente para hacer presencia en todo el territorio nacional. El segundo era un cuerpo de reserva que se llamaba al servicio en tiempos de convulsión interna o invasión extranjera para dar apoyo al ejército regular; fue un cuerpo híbrido porque sus miembros se reclutaban entre los vecinos de los distritos parroquiales, quienes asistían los fines de semana a su entrenamiento (ejercicios doctrinales) y el resto del tiempo se dedicaban a sus actividades cotidianas. En su caso las ordenanzas solo se les aplicaban en servicio activo y el mando era más flexible y fuertemente modelado por el personalismo de sus comandantes, quienes eran los que tenían la influencia suficiente en un distrito para convocar a sus paisanos a enrolarse en las compañías?.

A pesar del reducido pie de fuerza regular, las provincias del Cauca (Buenaventura, Cauca, Popayán y Pasto), contaron permanentemente, desde 1832, con unidades militares, las cuales se complementaban con el llamado al servicio de compañías y piquetes de guardia nacional. Las razones de esta constante presencia militar se debieron, primero, a la exigencia de batallones en Pasto o Túquerres, en límites con el Ecuador, por causa de

8 Las llamadas provincias del Cauca eran un conjunto de cuatro provincias ubicadas al suroccidente de la Nueva Granada (Cauca, Buenaventura, Popayán y Pasto). Posteriormente, de la mano de los procesos de descentralización administrativa a inicios de los años cincuenta, se erigieron dos más (Túquerres y Barbacoas). Esta una denominación genérica para nominar aquel territorio que ha hecho escuela entre los historiadores colombianos, proceden de algunos intelectuales del siglo XIX, quienes para referirse a un área cultural borraron la amplia diversidad existente en aquellas territorialidades.

9 Luis Ervin Prado Arellano "La organización de los ejércitos republicanos en la Nueva Granada: Provincias del Cauca (1830-1855)" (tesis doctoral en Historia Latinoamericana, Universidad Andina Simón Bolívar, Ecuador, 2019), 82-240. 
los diversos roces fronterizos durante los años treinta y cuarenta; segundo, el suroccidente, después de concluidas las guerras de independencia, fue inestable políticamente, pues el consenso social, sostenido a lo largo del período colonial, se erosionó a partir de 1809 con ayuda de la emergencia de los discursos republicanos, que lentamente entraron en la opinión pública popular y sirvieron para cuestionar el orden social vigente y formas remanentes del dominio hispánico como la esclavitud, la deferencia social, entre otros. De esta manera se incubaron en la región diversas guerras civiles y levantamientos armados como la guerra de los Supremos (18391842), la de 1851, la guerra por la Federación (1859-1862) y asonadas indígenas, especialmente en Pasto $^{10}$.

Todas estas amenazas exigieron una presencia activa de unidades militares para responder a los diversos focos que cuestionaban abiertamente la autoridad del Estado y alteraban el orden social. De esta manera desde los primeros años de vida independiente en las "Provincias del Cauca", se institucionalizó la presencia de batallones o compañías del ejército o de la guardia nacional, quienes terminaron desempeñando actividades que contribuyeron a construir estatalidad en las diversas comarcas del suroccidente.

\section{El ejército republicano y el Despliegue del Estado en las PRo- vincias del CaUCa}

¿Cuáles fueron aquellas actividades que ayudaron a construir los procesos de estatalidad y estatalización en las Provincias del Cauca? Inicialmente se debe decir que la presencia de unidades militares en ciudades capitales como Popayán y Pasto fueron instrumentalizadas por las autoridades civiles para encargarlas de la vigilancia de los edificios públicos, las cárceles, los presidios, escolta de correos, rondas nocturnas, ante la carencia de un cuerpo de policía. Esto hizo sentir la presencia del Estado entre los habitantes de las provincias del Cauca.

10 Luis Ervin Prado Arellano, "Ecuador y la guerra civil de los Supremos en los Andes surcolombianos (1839-1842), Anuario de Historia Regional y de las Fronteras, Vol. 6 (2001), 65-86; Luis Ervin Prado Arellano, David Fernando Prado Valencia, Laura Helena Ramírez Tobar, Diarios de las guerras de mediados de siglo en las provincias del Cauca, 1851-1854 (Popayán: Editorial Universidad del Cauca, 2014), 13-45. 
Respecto a la vigilancia de edificios públicos, desde 1833 es evidente la institucionalización de dicha tarea en las fuerzas armadas, lo que obligó con frecuencia al gobernador de Popayán a llamar al servicio a miembros de la guardia nacional cuando se retiraban de la ciudad los batallones o compañías del ejército regular. Inmuebles como la gobernación, la casa de la Moneda, el tribunal superior, entre otros espacios administrativos, fueron objeto de permanente vigilancia ${ }^{11}$. La importancia de dicha actividad se hizo evidente en la manera como los funcionarios buscaron la forma legal para que entraran en servicio las milicias, a pesar de que la ley orgánica no contemplaba esta tarea ${ }^{12}$.

También la fuerza pública resguardó las cárceles y presidios del suroccidente, lo que contribuyó al fortalecimiento del monopolio legítimo de la violencia, entendido en el sentido del ejercicio privativo del Estado de aplicar justicia ${ }^{13}$. En general, las armas de la Nueva Granada custodiaron tales locales de castigo, trasladaron presos y condujeron pliegos judiciales.

11 Ver cartas de la jefatura militar de la provincia al gobernador, Popayán 17 de julio y 31 de julio de 1834, 10 de septiembre y 22 de octubre de 1834: ACC. AM. 1834. Paquete 24, legajo 25. Jefatura militar de la provincia, Popayán 10 de junio, 18 de julio y 26 de agosto de 1835: ACC. AM. 1835. Paquete 25, legajo 29; copiador de oficios del jefe militar de la provincia, Popayán 10 de octubre de 1837: ACC. AM. 1837. Paquete 27, legajo 38; ACC. AM. 1839. Paquete 29, legajo 21. Sobre esta misma situación para Pasto: carta comandancia en jefe de la división de operaciones sobre Pasto, cuartel general en Pasto a 18 de octubre de 1839: ACC. AM. 1839. Paquete 29, legajo 21; secretario de Guerra y Marina al gobernador de la provincia, Bogotá 2 de abril de 1839: ACC. AM. 1839. Paquete 29, legajo 45.

12 Carta jefatura militar de la provincia al señor gobernador, Popayán 18 de agosto de 1837: ACC. AM. 1837. Paquete 27, legajo 36; Secretaría de la Gobernación, Popayán 17 de abril de 1839: ACC. AM. 1839. Paquete 29, legajo 45. Por código del régimen provincial que determinó las condiciones en que la Gobernación podía llamar a la guardia nacional al servicio, siempre se buscó la forma para que sirvieran custodiar los edificios públicos en momentos de ausencia del ejército. Ver ACC. AM. 1840. Paquete 31, legajo 47; ACC. AM. 1843. Paquete 37, legajo 27; ACC. AM. 1844. Paquete 38, legajo 5; ACC. AM. 1846. Paquete 41, legajo 75 bis; ACC. AM. 1847. Paquete 43, legajo 85; ACC. AM. 1849. Paquete 46, legajo 48; ACC. AM. 1849. Paquete 47, legajo 73; ACC. AM. 1851. Paquete 50, legajo 50.

13 Carta de la jefatura política, Caloto 18 de diciembre de 1833: ACC. AM. 1833. Paquete 23, legajo 13; jefatura militar de la provincia, Popayán 14 de junio de 1834: ACC. AM. 1834. Paquete 24, legajo 25; jefatura militar de la provincia, Popayán 19 de marzo de 1834: ACC. AM. 1834. Paquete 24, legajo 8; comandancia de la $1^{\text {a }}$ columna de la $1^{\text {a }}$ división, Popayán 14 de agosto de 1842: ACC. AM. 1842. Paquete 35, legajo 44; jefatura política Almaguer 22 de febrero de 1852 y 26 de marzo de 1852: ACC. AM. 1852. Paquete 52, legajo 41. Sobre presidios: comandancia general del Departamento del sur y jefe de la división del ejército, cuartel general en Pasto a 15 de junio de 1849: ACC. AM. 1849. Paquete 47, legajo 73. 
En esta misma clave, ayudaron a fortalecer la administración de correos. En múltiples ocasiones piquetes de soldados sirvieron de escoltas a las valijas y a los fondos destinados al sostenimiento de la burocracia y de las mismas unidades militares acantonadas en la región. El 19 de julio de 1839 la gobernación de Buenaventura aprobó el nombramiento de una escolta militar para al correo del distrito de Micay en la costa del Pacífico, por "las sospechas fundadas" de haber partidas de salteadores en la zona ${ }^{14}$. Dicha tarea sirvió para dar credibilidad al servicio de encomienda estatal, como lo expresó en octubre de 1841 el gobernador de Popayán al solicitar que, a raíz de un asalto del correo por Jambaló, los vecinos de las localidades no deseaban poner su correspondencia en él. Por ello pedía una escolta militar hasta Cali para ayudar así a disipar las dudas ${ }^{15}$. De esta manera se fue institucionalizando el acompañamiento militar en momentos de convulsión política o cuando se tenían indicios de la existencia de partidas de salteadores ${ }^{16}$. Su importancia en este servicio se evidenció en tiempos de guerra, cuando los correos colapsaban sin no contaban con apoyo militar, como sucedió con la valija de Neiva - Popayán, que se represó en el último semestre de 1841, al no contar con la adecuada vigilancia ${ }^{17}$.

14 Comandancia en jefe de la $3^{a}$ columna del ejército, cuartel general de Popayán 19 de julio de 1839 y comandancia de la $3^{a}$ columna del ejército y jefatura militar de la provincia al gobernador, Popayán 30 de marzo de 1839, en: ACC. AM. 1839. Paquete 29, legajo 45. Respecto de escoltas para conducción de dinero: copiador de oficios con el señor jefe militar de la provincia, Popayán 29 de marzo de 1842: ACC. AM. 1841. Paquete 32, legajo 56.

15 Ver en Copiador de oficios con el señor jefe militar de la provincia, Popayán 27 de octubre de 1841: ACC. AM. 1841. Paquete 32, legajo 56. En efecto el asalto a los correos durante tiempos de convulsión política no fue extraordinario, de ahí que se asumiera como indispensable la escolta armada para el envío de las valijas. En la guerra de los Supremos, se hizo perentorio para el correo en tránsito por Timbío al punto de que las autoridades militares se quejaron porque tales funciones atentaban con las operaciones militares. Ver: carta de la comandancia en jefe de la división de reserva, cuartel

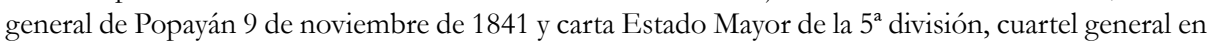
Popayán a 29 de octubre de 1841: ACC. AM. 1841. Paquete 33, legajo 62. Administración principal de correos, Popayán 9 de noviembre de 1841, solicitando para el 'correista' de Pasto, escolta hasta los Árboles por temor a los facciosos: ACC. AM. 1841. Paquete 33, legajo 73. Para la rebelión de 1851, en copiador de oficios de la Secretaría de Estado en el despacho de guerra y marina, Popayán junio 11 de 1851: ACC. AM. 1849. Paquete 46, legajo 48 y carta de la comandancia del medio batallón $3^{\circ}$ de la guardia nacional auxiliar de la provincia, Quilichao 3 de agosto de 1851: ACC. AM. 1851. Paquete 50 , legajo 50 .

16 Gobernación de La Buenaventura, Cali 7 de agosto de 1841: ACC. AM. 1841. Paquete 33, legajo 63; gobernación de la provincia de La Buenaventura, sala de despacho en Cali a 27 de mayo de 1847: ACC. AM. 1847. Paquete 43, legajo 83. También en 1850, se dispuso una escolta al correo, por la aparición de una partida de malhechores entre los límites de la parroquia de Palmira a la de Quilichao: gobernación de La Buenaventura, Cali 19 de septiembre de 1850, en: ACC. AM. 1850. Paquete 49, legajo 84 .

17 Ver cartas fechadas en Neiva del 7 de septiembre a 30 de diciembre de 1841: ACC. AM. 1841. Paquete 33, legajo 62. 
A la actividad mencionada se agregó el patrullaje urbano. Por ejemplo, el 24 de septiembre de 1841 el gobernador de Popayán, José María Galavís, llamó al servicio a la guardia local para vigilar la ciudad ${ }^{18}$. Similares funciones hicieron las milicias en las cabeceras de los distritos parroquiales de Caloto, Almaguer y el Trapiche. En general, este servicio se usó en tiempos de guerras civiles, o poco después de concluidas, pues era necesario mantener los cascos urbanos custodiados para evitar desórdenes por la presencia, aún en los alrededores de la ciudades, de partidas rebeldes que medraban la oportunidad para asaltar sus inmediaciones ${ }^{19}$.

Si bien la actividad de patrulla no fue regular, todo indica que en ciertos momentos se conformaron rondas nocturnas para prevenir desórdenes o por haber indicios de partidas de salteadores urbanos ${ }^{20}$. Tal acción fue replicada por las autoridades parroquiales, que recurrían en su caso a las compañías de guardia nacional del distrito, para desempeñarse como policía rural, a pesar que este tipo de fuerza no se institucionalizó en el período de estudio. Pero esto no eximió algunas tentativas de constituir estas patrullas a fines de 1846, cuando la jefatura política de Almaguer, en cabeza del señor José Ignacio Lemos, promovió la formación de un cuerpo de policía con miembros de la guardia nacional, compuesta por una escuadra de caballería (un inspector y cinco comisarios) y dos de infantería (un inspector y siete comisarios cada una). El cuerpo, según el funcionario, se necesitaba "para imponer respeto a las cuadrillas inmorales de negros y los salteadores que no deja de haber ocultos en los montes"21. Similar

18 Copiador de oficios, Popayán 24 de septiembre de 1841: ACC. AM. 1841. Paquete 32, legajo 56.

19 Carta jefatura política del cantón de Caloto, septiembre 24 de 1842: ACC. AM. 1842. Paquete 35, legajo 4. También véase: Copiador de oficios, Popayán 4 de octubre de 1841: ACC. AM. 1841. Paquete 32, legajo 56; informe al jefe político de Almaguer 27 de febrero, 26 de marzo y de 26 de abril de 1852: ACC. AM. 1852. Paquete 52, legajo 41.

20 Jefatura militar de la provincia al gobernador, Popayán 22 de octubre de 1834: ACC. AM. 1834. Paquete 24 , legajo 25 ; carta jefatura militar de la provincia y comandancia militar en jefe de la $1^{\mathrm{a}}$ columna de la división, Popayán 25 de julio de 1842: ACC. AM. 1842. Paquete 35, legajo 44; copiador de oficios con el comandante general de armas de la provincia, Popayán 9 de enero de 1843: ACC. AM. 1843. Paquete 36, legajo 69; Secretaría de Estado en el despacho de Gobierno, sección contabilidad, al gobernador de la provincia, Bogotá 27 de junio de 1849: ACC. AM. 1849. Paquete 47, legajo 75. El alcalde parroquial de Florida conformó una vigilancia nocturna, al tener información que continuamente pasaban por la localidad grupos de hombres en horas de la noche sin conocer su objeto: alcaldía parroquial de Florida 14 de abril de 1851: ACC. AM. 1851. Paquete 50, legajo 50.

21 Informe de formación de cuerpo de policía en Almaguer: ACC. AM. 1847. Paquete 43, legajo 82. 
medida se hizo en Caloto, para hacer correrías en varias zonas montuosas y cenagosas de la jurisdicción contra la población rural, negra, mulata y mestiza que vivía dispersa y sin sujeción, dedicándose a múltiples actividades clandestinas, como el cultivo del tabaco, el abigeato y la destilación de aguardiente ${ }^{22}$.

Relacionado también con actividades de policía, el reclutamiento de hombres para la fuerza regular fue una manera indirecta a través de la cual el ejército sirvió a los funcionarios públicos. Si bien las normas emitidas del período contemplaban las exenciones a la conscripción, también determinaron quiénes eran los sujetos perentorios para el reclutamiento tanto en tiempos de paz como en convulsión política, como los vagos y mal entretenidos. Dicha política fue claramente determinada con la ley del 2 de junio de 1842 , en su capítulo $2^{\circ}$ de la conscripción, donde especificó claramente qué personas debían reclutarse: los vagos, los solteros insubordinados de vida escandalosa, los notoriamente sindicados de costumbres perniciosas, los jóvenes que no ayudaran a sus padres, los casados que abandonaron a sus mujeres o le den mala vida o estén amancebados y los padres que no respondan por sus hijos ${ }^{23}$. En otras palabras, la ley se relacionada con aquellos remanentes morales de los autos de buen gobierno colonial, que exigían una conducta a los individuos bajo los preceptos cristianos de vivir en policía y campana, los cuales fueron resignificados por la ideología republicana en boga ${ }^{24}$.

No obstante, si bien la ley de 1842 fue taxativa para el reclutamiento de este tipo de hombres, desde tiempo atrás la conscripción de vagos y mal entretenidos fue parte de la moneda corriente de los funcionarios parroquiales, quienes vieron en la captura y remisión al ejército una manera de "extirpar" del cuerpo social a sujetos considerados una carga para la socie-

22 Jefatura política del cantón, Caloto 17 de abril de 1847: ACC. AM. 1847. Paquete 43, legajo 82.

23 Ley de junio 2 de 1842, adicional a las orgánicas del ejército y guardia nacional, en: Codificación Nacional de todas las leyes de Colombia, tomo 9 (Bogotá: Imprenta Nacional, 1927), 392-399.

24 Ángela Pérez Villa, Disorderly Love: Illicit Friendships, Violence, and Law in a Slave Society at War, Popayán-Colombia, 1809-1830 (tesis doctoral en Historia, Universidad de Michigan, 2017), 135-140; Christon I. Archer, "To Serve the King: Military Recruitment in Late Colonial Mexico", The Hispanic American Historical Review, Vol. 55, No. 2 (1975), 226-250. 
$\mathrm{dad}^{25}$. Su acción pone de manifiesto una tradición que finca sus raíces en la ilustración del siglo XVIII, que consideró al ejército como un dispositivo para disciplinar los hombres y convertirlos en útiles para la sociedad. De hecho, se creía que la vida en el cuartel con su rígida disciplina y el respeto a las jerarquías convertía a los reclutas, como lo señaló el secretario de guerra de 1853, al retornar a sus hogares, en: “[...] laboriosos, obedientes a la autoridad y, sobre todo, con ideas y prácticas de honradez y probidad que tan comunes son en los militares"26.

La actividad de policía rural y urbana se relacionó con otro proceso de estatalidad: el fortalecimiento de la capacidad extractiva del Estado. En nuestro caso de estudio, la fuerza pública intentó controlar el cultivo y comercio del tabaco, especialmente en el área comprendida entre Palmira y Caloto hasta finales de la década del cuarenta, cuando el gobierno liberal abolió el estanco de la hoja ${ }^{27}$. Desde los años veinte existen registros de la colaboración del ejército y las milicias en el control de la hoja ${ }^{28}$. En términos generales, el ejército y las guardias nacionales de Caloto, Celandia, Palmira, Candelaria, Cali y Popayán terminaron brindando apoyo a los guardas de tabaco, por ser insuficientes para controlar una vasta área comprendida entre Caloto y Palmira, donde se concentró la mayor cantidad de plantaciones clandestinas de tabaco en los bosques de la región ${ }^{29}$. Por una

$25 \mathrm{Al}$ respecto, véase carta del juzgado municipal del cantón de Supía, 18 de abril de 1832 al gobernador de la provincia, en: ACC. AM. 1832. Paquete 21, legajo 9; carta de la jefatura política del circuito, Cartago, 17 de octubre de 1833, al gobernador de Popayán: ACC. AM. 1833. Paquete 23, legajo 15; carta (del cantón de Almaguer, no especifica el sitio y la autoridad que lo remite) $1^{\circ}$ de julio de 1833 , al gobernador de la provincia: ACC. AM. 1833. Paquete 23, legajo 25; carta de la jefatura política de Supía, 26 de octubre de 1834: ACC. AM. 1834. Paquete 24, legajo 41.

26 Informe del secretario de Estado del despacho de Guerra de la Nueva Granada al Congreso constitucional de 1853 (Bogotá: Imprenta Neogranadino, 1853), 11-12.

27 Según John Harrison citado por Margarita Pacheco, la actividad desarrollada por colonos "libres de todos los colores" producía de forma clandestina "la doceava parte del total de la cosecha tabacalera" en el valle geográfico: Margarita Pacheco, La fiesta liberal en Cali (Cali: Universidad del Valle, 1992), 27.

28 Carta del ejército permanente $1^{a}$ comandancia del batallón, Popayán 11 de octubre de 1833: ACC. AM. 1833. Paquete 23, legajo 32; jefatura militar de la provincia, Popayán a 31 de julio de 1834 y de 10 de septiembre de 1834: ACC. AM. 1834. Paquete 24, legajo 25. Jefatura militar de la provincia, Popayán 11 de julio de 1834: ACC. AM. 1834. Paquete 24, legajo 8.

29 Sobre el estanco de tabaco para el siglo XIX: Luis F. Sierra, El tabaco en la economía colombiana del siglo XIX (Bogotá: Universidad Nacional de Colombia, 1971). 
parte, entregaron armas a los guardas, pero también se terminaron involucrando en las correrías, penetrando en los "montes", erradicando cultivos y quemando caneyes para el secado de la hoja ${ }^{30}$.

A lo largo del período de estudio fueron constantes los requerimientos por la administración de tabaco, de cuerpos armados, inicialmente para destacamentos de vigilancia en puntos neurálgicos de la región, como Pílamo, El Palo, puente de Japio, entre otros sitios de Caloto. No obstante, a finales de la década del treinta y en la siguiente pasaron a la estrategia de hacer penetraciones a las áreas boscosas con piquetes de más de 25 hombres, apoyados por baquianos y guardas para erradicar las plantaciones ${ }^{31}$.

A inicios de los cuarenta se percibió un mayor nivel de conflicto entre los representantes de la hacienda estatal y los habitantes de aquellas áreas selváticas dedicados al cultivo de tabaco, ya que allí se refugiaron diversos hombres comprometido en la guerra de los Supremos que, armados, retaron las entradas de la fuerza pública al territorio. Esta situación hizo endurecer las correrías, que tuvieron una mayor efectividad en localizar y destruir plantaciones de tabaco ${ }^{32}$. Tales incursiones no dejaron de generar actos arbitrarios, que en algunos casos llegaron a oídos de las autoridades judiciales, quienes buscaron esclarecer los hechos. Sin embargo, los

30 Sobre entrega de armas al resguardo: jefatura militar de la provincia, Popayán 19 de marzo de 1834 y Popayán 26 de octubre de 1834: ACC. AM. 1834. Paquete 24, legajo 8; Secretaría de Estado en el despacho de Guerra y Marina, al gobernador de la provincia, Bogotá 27 de enero de 1835: ACC. AM. 1835. Paquete 25, legajo 24; factoría de tabacos de la provincia, Palmira 29 de diciembre de 1834 y Palmira 10 de enero de 1835: ACC. AM. 1835. Paquete 25, legajo 53.

31 Jefatura política del cantón, Cali 5 de marzo de 1836: ACC. AM. 1836. Paquete 26, legajo 35. Carta de la jefatura política de Caloto 13 de febrero de 1836, 12 de marzo de 1836 y 22 de abril de 1836: ACC. AM. 1836. Paquete 26, legajo 36. Jefatura política del cantón, Caloto 20 de febrero de 1836: ACC. AM. 1836. Paquete 26, legajo 41. Otros casos similares escritos por la jefatura militar de la provincia en Popayán entre enero y marzo de 1839: ACC. AM. 1839. Paquete 29, legajo 21.

32 Los primeros informes pormenorizados se pueden ver en la carta de la jefatura política del cantón de Caloto, 3 de febrero de 1844, 10 de febrero de 1844 y 24 de febrero de 1844: ACC. AM. 1844. Paquete 38, legajo 48; jefatura política de Caloto 25 de septiembre de 1846 y el de 18 de julio de 1846 (este documento viene acompañado del primer diario identificado que relata día a día las acciones que emprendieron en la correría); jefatura política de Caloto $1^{\circ}$ de agosto de 1846 ; “diario de operaciones realizado por los individuos de la guardia de este cantón comprendidos desde el 18 de junio a la fecha, en el corriente año de 1846"; "diario de operaciones practicadas por la guardia nacional auxiliar que se halla en servicio activo en este cantón, comprensivo desde el 12 de mayo principiado hasta la fecha en el corriente año de 1846", véase: ACC. AM. 1846. Paquete 41, legajo 75 bis. Para otros diarios: ACC. AM. 1848. Paquete 45, legajo 67 bis. 
informes sobre el tema son exiguos en narrar la violencia desplegada por parte de los agentes del Estado sobre los habitantes de la zona ${ }^{33}$; tareas de erradicación de cultivos clandestinos también se presentaron en Sopinga, jurisdicción de Cartago, en el hoy valle de Risaralda, y en el Castigo, valle del Patía ${ }^{34}$.

Similares actividades también las desempeñó en el control de la producción clandestina de aguardiente y contrabando de mercancías ${ }^{35}$. El ejército fue utilizado para someter a los denominados "trapicheros", los fabricantes clandestinos de aguardiente, ampliamente extendidos a lo largo y ancho de las provincias caucanas. Por esto, a veces antes de establecer el estanco de aguardiente en una localidad, se enviaba un cuerpo armado para evitar una asonada, pues la medida afectaría la actividad económica de la comunidad $^{36}$. También la fuerza pública se empleó contra los "rastros", sitios en los que se vendía carne de res que no cancelaban los derechos de carnicería e incluso eran de dudosa procedencia ${ }^{37}$.

33 Comandancia en jefe de la $3^{\text {a }}$ columna del ejército y jefatura militar de la provincia, cuartel general Popayán 28 de abril de 1837: ACC. AM. 1837. Paquete 27, legajo 36. Sobre atropellos: jefatura política, Caloto 29 de octubre de 1848: ACC. AM. 1848. Paquete 45, legajo 67 bis.

34 Sobre Sopinga: Jefatura Militar de la provincia, Cali 24 de enero de 1834: ACC. AM. 1834. Paquete 24, legajo 8; Secretaría de Estado en el despacho de Guerra y Marina, Bogotá 27 de enero de 1835: ACC. AM. 1835. Paquete 25, legajo 24; proceso iniciado el 13 de enero de 1840 contra Antonio Loaiza por resistencias que hizo en el sitio de Sopinga: ACC. AM. 1840. Paquete 30, legajo 39. Para el Castigo: Estado Mayor de la $3^{a}$ columna, Popayán 26 de septiembre de 1833: ACC. AM. 1833. Paquete 23, legajo 32.

35 Carta de la Secretaría de Estado en el despacho de Guerra y Marina, Bogotá $1^{\circ}$ de abril de 1835: ACC. AM. 1835. Paquete 25, legajo 24; copiador de oficios con el señor jefe militar de la provincia, Popayán 29 de octubre de 1842: ACC. AM. 1841. Paquete 32, legajo 56; Carta de la Jefatura política, Caloto 29 de octubre de 1849: ACC. AM. 1848. Paquete 45, legajo 67 bis. Los registros documentales señalan el alto nivel de defraudación, por ejemplo, en mayo de 1849, se informó que en Quilichao había más de treinta destiladores clandestinos. Cuando la administración intentó poner fin a un "fraude escandaloso", se formó un motín que obligó a llamar la guardia nacional. Véase: carta de la jefatura política del cantón, Caloto 5 de mayo de 1849 y el decreto de la jefatura llamando al servicio a la guardia nacional, Caloto 4 de mayo de 1849: ACC. AM. 1849. Paquete 47, legajo 84. Sobre el control de contrabando, las autoridades establecieron destacamentos en el puente del Cauca y Calicanto para vigilar la entrada de mercancías extranjeras a Popayán. Ver: copiador de oficios con el señor jefe militar de la provincia, Popayán 29 de octubre de 1842, en: ACC. AM. 1841. Paquete 32, legajo 56.

36 En 1835 se solicitaba para el establecimiento de la ley orgánica de aguardiente llamar al ejército permanente para el apoyo de dicha medida. ACC. AM. 1835. Paquete 25, legajo 24.

37 Sobre la evasión por parte de los sectores subalternos de varios ramos de hacienda: Margarita Pacheco, La Fiesta Liberal..., 40; Alonso Valencia Llano, Dentro de la ley. Fuera de la ley. Insurgencia social en el valle del Cauca, 1810-1854 (Cali: Universidad del Valle, $2^{a}$ edición, 2016), 137-146. 
El proceso de despliegue de la estatalidad en los años treinta y cuarenta en la búsqueda de fortalecer la hacienda pública en la región, exigió la aplicación de la normativa republicana. En el ejercicio de controlar la evasión, las autoridades cuestionaron las formas de vida de las poblaciones dedicadas a tales actividades; de esta manera, se estigmatizó la población y la convirtió en sujeto de castigo. En el caso aludido, los hombres y mujeres de aquellos poblados fueron considerados "ladrones" y "abigeos" que andaban armados e intimidando a los vecinos. Se referían a sus asentamientos como "palenque de pícaros y asesinos", o "madriguera", aludiendo a la tradición hispánica de pueblos no sujetos y rebeldes a su majestad ${ }^{38}$. Así mismo, se usaron otros términos como "amotinados" o "malhechores de Sopinga", "facción contrabandista de Sopinga"; "contrabandistas amotinados en..." "39. Toda esta semántica expresa un conflicto entre el Estado que desea imponer un "orden” y su ejercicio homogeneizador por vía de la ley, y otro vernáculo, con sus formas alternativas de vida, que los procesos de estatalidad y estatalización terminaron criminalizando y marginalizando.

Similar actuación hizo la fuerza pública en otros sitios de la geografía caucana ${ }^{40}$. En el proceso, de la mano de sus unidades armadas, el Estado

38 Las expresiones aludidas para el sitio de Gallinazas: jefatura política del cantón, Palmira 6 de mayo de 1833, donde se reproduce una carta del juez parroquial de Buchitolo y jefe municipal del cantón, Cali 8 de mayo de 1833: ACC. AM. 1833. Paquete 23, legajo 25. Jefatura militar de la provincia, Popayán 12 de junio de 1832, en: ACC. AM. 1833. Paquete 23, legajo 32.

39 Sobre las expresiones hacia los moradores de Sopinga, se pueden leer: carta del jefe político municipal del Cantón, Cartago a 3 de septiembre de 1833: ACC. AM. 1833. Paquete 23, legajo 25; carta del jefe político municipal del cantón, Cartago 3 de junio de 1833: ACC. AM. 1833. Paquete 23, legajo 2; carta comandancia de armas de la guarnición del valle del Cauca, Cali 8 de mayo de 1833, Cali 14 de mayo de 1833 y Cali 17 de mayo de 1833, Cartago junio 17 de 1833, Cartago julio 17 de 1833: ACC. AM. 1833. Paquete 23, legajo 32; carta de la secretaría de Estado en el despacho de Guerra y Marina, Bogotá 27 de enero de 1835: ACC. AM. 1835. Paquete 25, legajo 24. En general, a los sitios objeto de punición se les llamó genéricamente "palenques": copiador de oficios con el señor jefe militar de la provincia: ACC. AM. 1841. Paquete 32, legajo 56.

40 Uno de estos casos fue las salinas de San Miguel en jurisdicción de Tuluá, cerca de la parroquia de Bugalagrande, donde los negros esclavos se habían autonomizado y administraban la mina por su propia cuenta al fallecer su amo. Pero la situación que hizo intervenir al Estado, fue por recibir esclavos prófugos y sujetos con sospechas de ser criminales: carta de la jefatura política del cantón, Tuluá 6 de octubre de 1834 y de $1^{\circ}$ de noviembre de 1834, y jefatura política del cantón, Buga 16 de noviembre de 1834 y 21 de diciembre de 1834: ACC. AM. 1834. Paquete 24, legajo 27. También fue objeto de una mirada recelosa, pero sin actuación del Estado, tal vez por su lejanía, el sitio de Escancé, ubicado en la parte alta del río Putumayo: carta de la comandancia de la $3^{a}$ columna del ejército, sección $2^{\mathrm{a}}$, Concejo Municipal de Pasto $1^{\circ}$ de septiembre de 1834 y carta del teniente Maria- 
hizo presencia en sus márgenes, intentó imponer su lógica y "civilizar” a los hombres y mujeres calificados de bandidos, abigeos, salteadores, etc. Legitimizó así una biopolítica que tuvo como máximo corolario la estigmatización de los individuos de ascendencia africana, quienes desde los años cuarenta fueron objeto de diversas leyes que buscaron prolongar su sujeción especialmente a los manumitidos por la ley de libertad de vientres de 1821, al considerarlos no estar en la capacidad de asumir responsablemente su libertad ${ }^{41}$.

En este mismo horizonte se inscribió la persecución contra partidas de bandidos o cuadrillas de salteadores ${ }^{42}$. Sin embargo, a pesar de la recurrencia del fenómeno en ciertas territorialidades del Cauca, este se encuentra más bien relacionado con los conflictos internos. Raúl Fradkin identificó una correlación en la campaña bonaerense, al señalar que las bandas de asaltantes se nutrieron de los desertores del ejército que huían de la rígida disciplina o de los rebeldes derrotados, que al dispersarse formaban pequeñas unidades que no regresaban a la vida civil y terminaban viviendo del robo a caseríos, a transeúntes y a haciendas, refugiándose en áreas bos$\operatorname{cosas}^{43}$. De hecho, las referencias de bandoleros y asaltantes en la región

no Guevara al gobernador de la provincia de Popayán, El Trapiche 9 de agosto de 1834: ACC. AM. 1834. Paquete 27 , legajo 8.

41 Parte de las razones por las cuales la población de ascendencia africana fue objeto de tales medidas, se debió a su participación en el bando rebelde durante la guerra de los Supremos (1839-1842). María Camila Díaz, Salteadores y cuadrillas de malhechores. Una aproximación a la acción colectiva de la "población negra" en el suroccidente de la Nueva Granada, 1840-1851, (Popayán: Editorial Universidad del Cauca, 2015), 126-133.

42 Eric Hobsbawm, historiador pionero del bandidismo, lo interpretó como una forma de luchas pre-política, en reacción a las transformaciones del mundo rural a un sistema capitalista. Sin embargo, su interpretación canónica ha sido fuertemente criticada. Eric Hobsbawm, Bandidos (Barcelona: Crítica Editorial, 2011); Rebeldes Primitivos. Estudio sobre las formas arcaicas de los movimientos sociales en los siglos XIX y XX (Barcelona: Editorial Ariel, 1983), 9-52. Para una revisión crítica del bandidismo en América latina: Carlos Aguirre, Charles Walker, Bandoleros, abigeos y montoneros. Criminalidad y violencia en el Perú, siglos XVIII-XX (Lima: Instituto de Apoyo Agrario, 1990); Gilbert M. Joseph, "On the Trail of Latin American Bandits: A reexamination of peasant resistance", Latin American Research Review, Vol. 25, No. 3 (1990), 7-53; Richard W. Slatta, "Bandits and rural social history: A comment on Joseph", Latin American Research Review, Vol. 26, No 1 (1991), 145-151.

43 Raúl O. Fradkin, "Bandolerismo y politización de la población rural de Buenos Aires tr as la crisis de la independencia (1815-1830)", Nuevo mundo mundos nuevos, No 5 (2005), disponible http:// nuevomundo.revues.org/document309.html; Raúl O. Fradkin y Silvia Ratto, "Desertores, bandidos e indios en la frontera de Buenos Aires, 1815-1819”, Secuencia, No 74, (2009), 11-41. 
aparecen con frecuencia en los meses y años posteriores al concluir un conflicto interno.

Tabla 1. Frecuencia de informe de informe de bandidos y partidas de salteadores en las "Provincias del Cauca", 1830-1852.

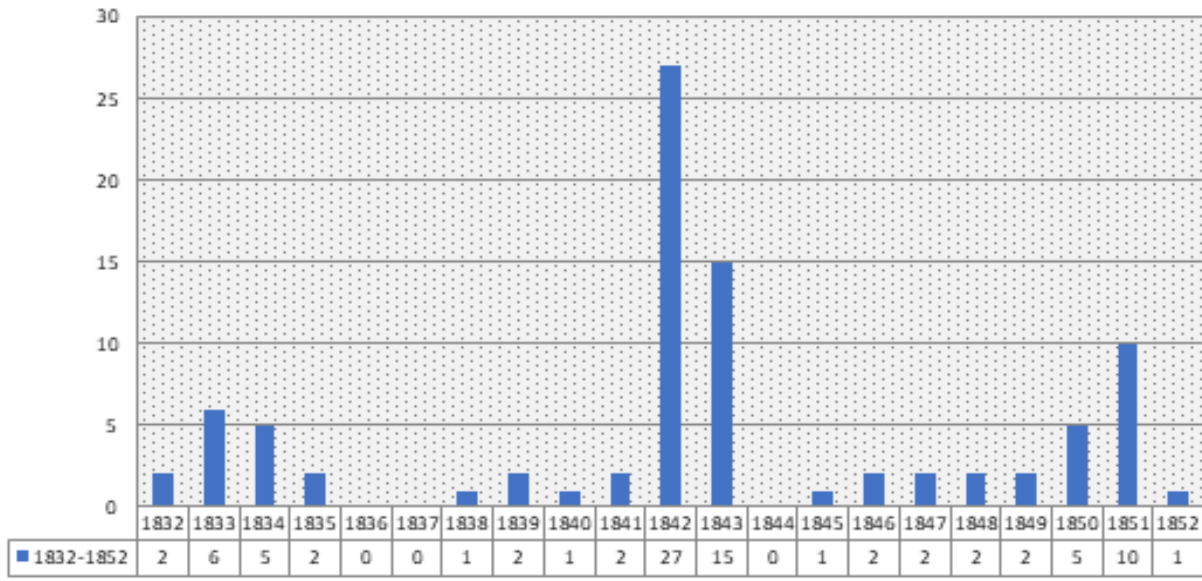

Fuente: ACC. AM. 1832. Paquete 21, legajo 9; ACC. AM. 1833. Paquete 23, legajo 15, 25, 32 (varios documentos); ACC. AM. 1834. Paquete 24, legajo 8, 27 (varios documentos); ACC. AM. 1835. Paquete 25, legajo 24 (varios documentos); ACC. AM. 1839. Paquete 29, legajo 21; ACC. AM. 1840. Paquete 30, legajo 39; ACC. AM. 1840. Paquete 31, legajo 46; ACC. AM. 1841. Paquete 32, legajo 56 (varios documentos); ACC. AM. 1841. Paquete 33, legajo 63; ACC. AM. 1842. Paquete 34, legajo 41; ACC. AM. 1842. Paquete 35, legajo 43 (varios documentos), 44 (Varios documentos), 45, 47 (varios documentos); ACC. AM. 1842. Sin Indice; ACC. AM. 1843. Paquete 36, legajo 18, 19, 24, 26 (varios documentos); ACC. AM. 1843. Paquete 37, legajo 47, 67, 69 (varios documentos), 70 (varios documentos), 72 (varios documentos), 74 (varios documentos); ACC. AM. 1843. Documentos de diversas comandancias del ramo militar; ACC: AM. 1843. Documentos de diversas dependencias dl ramo militar, Bis; ACC. AM: 1843. Diversos documentos del batallón Neira No 3º ACC. AM. 1846. Paquete 40, legajo 47, 65; ACC. AM. 1846. Paquete 41, legajo 75 bis (varios documentos); ACC. AM. 1848. Paquete 45, legajo 67bis (varios documentos); ACC. AM. 1849. Paquete 46, legajo 48 (varios documentos); ACC. AM. 1850. Paquete 49, legajo 69, 76 (varios documentos), 81 (varios documentos), 84; ACC. AM. 1851. Paquete 50, legajo 50; ACC. AM. 1851. Paquete 57, legajo 57, 58, 67; ACC. AM. 1851. Comunicaciones gobernación de Túquerres (varios documentos);

ACC. AM. 1851. Documentos de las gobernaciones de las provincias de Popayán, Cauca y Pasto.

La tabla 1 indica cómo la presencia de grupos etiquetados como bandidos, aumentó en tiempos de conflictos internos (1839-1842 y 1851) y en los años inmediatamente posteriores a su finalización. Este hecho sugiere que, cuando concluían las guerras civiles, gran cantidad de excombatientes desarraigados territorial y comunalmente, terminaban forjando lazos de solidaridad sobre las antiguas unidades armadas que terminaron siendo el vínculo para formar pequeñas bandas que delinquían para sobrevivir, al desertar o ser derrotados ${ }^{44}$. Un ejemplo de esto son el levantamiento lide-

44 Sobre informes de soldados desertores que se refugiaron en sitios inhóspitos, formando en algunos casos bandas de salteadores, véase: carta del Sr. jefe municipal del cantón de Cali a 8 de mayo de 
rados por antiguos rebeldes de la Guerra de los Supremos, José Antonio Tascón, artesano de Cartago, y Bernabé Rincón, labrador de Santa Ana, entre el 11 y 20 de abril de 1842, que asaltaron varias haciendas del área de Caloto, o los actos presentados entre agosto y diciembre de 1854, en Cali y otras localidades del valle como en Palmira ${ }^{45}$.

Pero no todos los grupos de bandoleros en las provincias del Cauca se deben interpretar bajo la perspectiva de bandido social de E. Hobsbawm, sino más bien como asociaciones que buscaban lucro ${ }^{46}$. En todo caso, independientemente de si sus acciones tuviesen o no contenido político, su presencia alteraba la tranquilidad de una localidad y su desarticulación fue llevada a cabo por las guardias nacionales, que se convirtieron en garantes del control social y territorial del Estado en varias parroquias. Un ejemplo de lo anterior lo encontramos en la carta fechada el 28 de noviembre de 1842, por el comandante del escuadrón Patía, el coronel Manuel M. Delgado, al gobernador de la provincia de Popayán, en la cual señalaba la importancia de mantener la unidad de combate activa y disciplinada, porque:

[...] Es un cuerpo que pude llamarse con razón aguerrido, ya que temen los enemigos del orden, no sólo por el valor que han manifestado, en todas ocasiones sino también por su constante adhesión y fidelidad al gobierno, aunque han desaparecido los facciosos V. S. sabe que todavía hay algunas pequeñas partidas que causan males, principalmente en las parroquias distantes de la capital, muchas de ellas en el estado de desmoralización en que la rebelión ha dejado los pueblos, es de temer que por mucho

1833, al gobernador de Popayán, donde informó que el coronel Apolinar Morillo capturó un soldado desertor, Justo Aquino, quien dijo había sido seducido a desertar por Bartolo Lora, habitante de Gallinazas, quien había dado refugio a dos desertores más: ACC. AM. 1833. Paquete 23, legajo 25; también carta de la jefatura política del cantón, Cartago junio 22 de 1833: ACC. AM. 1833. Paquete 23, legajo 2.

45 María Camila Díaz, Salteadores y cuadrilla de..., 112-120: Jorge Castellanos, La abolición de la esclavitud en Popayán, 1832-1852 (Cali: Universidad del Valle, 1980) 68-71; ACC. AM. 1842. Paquete 35, legajo 42 y 43; ACC. AM. 1843. Paquete 36, legajo 18, 26 y 47; ACC. AM. 1843. Paquete 37, legajo 69, 70, 74 y 77; ACC. 1843, Criminal, signatura 1841.

46 María E. Argeri las ha denominado empresas privadas, para la norpatagonia, a asociaciones de bandoleros que sus acciones no tenían contenido político: María E. Argeri, "Violencia y legitimidad..., 173-174. 
tiempo habrán malhechores que será necesario perseguir. En ninguna otra parroquia, puede crearse otro cuerpo de milicias que sea capaz de reemplazar al escuadrón, los habitantes del campo detestan la profesión de las armas, se disgustan y huyen cuando los llaman al servicio, con pocos y nada temidos de los enemigos en los soldados de este cuerpo hay en el día espíritu militar, y han adquirido renombre. Por esta razón es que no he dudado en decir a V. S. en que deben conservarse este escuadrón i nada se costea, ni pierde quedando en el estado en que se halla, y por el contrario el gobierno puede contar con un cuerpo fiel y aguerrido que sabrá sostenerlo en toda ocasión. ${ }^{47}$

Así también lo expresó el jefe político de Palmira en una carta de abril de 1843, quien afirmó que sus guardias nacionales daban confianza a los habitantes de su cantón y sus actividades fueron fundamentales para someter la rebelión de Tascón en Caloto ${ }^{48}$. Igualmente, en mayo de 1842, el alcalde de la Sierra pidió no desacuartelar la compañía del distrito y recoger sus armas, por la presencia de bandoleros ${ }^{49}$. Por su parte, la jefatura política de Caloto en abril de 1851, por la aparición de ladrones del Bolo, llamó al servicio la guardia nacional para perseguirlos ${ }^{50}$.

Finalmente, una de las actividades desempeñadas por el ejército fue el servicio en obras públicas, la cual emergió de la ley de 2 de mayo de 1845, establecida por el presidente y general Tomás Cipriano de Mosquera, al constituir en la fuerza permanente el arma de los zapadores ${ }^{51}$. En el caso Popayán, esta nueva fuerza apareció tempranamente, pues, entre los meses de septiembre y octubre de 1846, el comandante general del departamento

47 Comandancia militar, al gobernador de la provincia, Patía 28 de noviembre de 1842: ACC. AM. 1842. Paquete 35, legajo 44.

48 Jefatura política del cantón al gobernador de Popayán, Palmira 24 de abril de 1843: ACC. AM. 1843. Paquete 37, legajo 74 .

49 Jefatura política del cantón al gobernador de Popayán, Palmira 24 de abril de 1843: ACC. AM. 1843. Paquete 37, legajo 74; jefatura política del cantón al gobernador de la provincia, Popayán 19 de mayo de 1842: ACC. AM. 1842. Paquete 35, legajo 47, respectivamente. De hecho, hay diversidad de informes al respecto de los servicios que prestaba la guardia nacional persiguiendo partidas de ladrones, bandoleros y fugitivos de la ley. Véase: jefatura política de Almaguer, $1^{\circ}$ de julio de 1833 en Almaguer: ACC. AM.1833, Paquete 23, legajo 25.

16850 Jefatura política al gobernador de Popayán, Caloto a 12 de abril de 1851: ACC. AM. 1851. Paquete 51, legajo 58.

51 Ley de 2 de mayo de 1845, que autoriza al Ejecutivo a organizar cuerpos de Zapadores: Codificación Nacional de, tomo 9, 69-71. 
del sur, general Lorenzo Estévez, solicitó al gobernador brindara su apoyo en la apertura del camino a Moscopán por Puracé, liderado por los hombres del batallón $1^{\mathrm{o}}$ de zapadores ${ }^{52}$.

La política de creación de zapadores fue la forma como Mosquera buscó fomentar las obras públicas, especialmente en la apertura o composición de caminos, mutando diversos batallones de infantería a esta arma con el apoyo de ingenieros y agrimensores extranjeros, que vinieron al país bajo su administración. De esta manera, unidades de infantería se transformaron a zapadores, como el batallón de infantería "Mutis" número 2, del que una compañía se dedicó a reparar el camino nacional de la provincia de Pasto a inicios de 1848, mientras otra trabajó en la parroquia de la Balsa en el cantón de Cartago en el norte de la provincia del Cauca y en el camino de Quindío ${ }^{53}$.

\section{LOS LÍMITES DE LA ESTATALIDAD}

Las diversas actividades desempeñadas por los cuerpos armados republicanos en las provincias del Cauca durante las primeras décadas de vida republicana señalan su centralidad en el proceso de construcción estatal. Las unidades militares, como ya se ha referenciado, desempeñaron funciones de policía, de fortalecimiento de la hacienda, de la justicia y ejercieron acciones de control social y territorial, en un período en el que sin duda alguna el régimen estatal era débil e incapaz de mantener un control desde su centro político ${ }^{54}$.

52 Gobernación de la provincia al comandante de general del departamento del sur, Popayán 7 de septiembre de 1846: ACC. AM. 1846. Paquete 40, legajo 65; carta de la comandancia general del departamento del sur al gobernador de la provincia; carta de la tesorería de guerra del departamento del sur al gobernador de la provincia, Popayán 16 de octubre de 1846; carta de la comandancia general del departamento del sur y en jefe de la $1^{\text {a }}$ división, Popayán 29 de septiembre de 1846, en: ACC. AM. 1846. Paquete 41, legajo 80; carta del Intendente general de guerra y marina al intendente del ejército y marina del departamento del sur, Bogotá 11 de noviembre de 1846, en: ACC. AM. 1846. Paquete 41, legajo 82.

53 Sobre los zapadores en Pasto, a fines de los 40, operaba una compañía del batallón Mutis en la provincia; en sus revistas de junio y agosto de 1848, se concluye que entre 54 y 48 hombres de tropa estuvieron dedicados a la composición del camino nacional de Pasto: ACC. AM. 1848. Paquete 44, legajo 2 y ACC. AM.1848. Paquete 45, legajo 69; sobre la composición del camino en la parroquia de la Balsa en Cartago: ACC. AM. 1848. Paquete 45, legajo 70; para el camino de Quindío: ACC. AM. 1847. Comunicación de la Secretaría de Guerra y Marina a la comandancia general del departamento del sur.

54 Miguel Ángel Centeno sostiene para el caso latinoamericano la incapacidad que tuvieron los Estados 
Lo anterior significa asumir el Estado como una construcción social, siempre contingente y nunca acabada, de lo que la sociedad del momento fue capaz de instituir. Por lo señalado, estudiar las funciones desempeñadas por las fuerzas armadas durante el período de estudio permite observar los procesos de estatalidad (la forma como el Estado hizo presencia en su capilaridad) y su estatalización (construyendo su institucionalidad). Pero si bien la exposición privilegió las actividades que desempeñó, no debe entender como éxito. Fue un proceso donde se presentaron disensos de todo tipo. Por ejemplo, los oficiales tanto del ejército como de guardia nacional, en diversas ocasiones, se negaron que sus hombres sirvieran de subalternos a los jueces parroquiales para llevar sumarios, pliegos o conducir reos de un distrito a otro. En este caso, tales conflictos no se deben entender como obstáculos para el establecimiento de la judicialidad pública, pues el despliegue estatal no es monolítico ni es un ejercicio de poder discrecional impuesto de arriba hacia abajo. Es un proceso de constitución permanente, en el cual la configuración de sus burocracias es el resultado de pugnas por constituir su institucionalidad y sus ámbitos de acción; mucho más en momentos en que la construcción e innovación de un marco normativo regulador de la sociedad estaba en marcha, que se expresó en la elaboración de códigos de cuño republicano buscando reemplazar las normativas monárquicas. No obstante, a pesar de las reticencias, el apoyo de la fuerza pública al sistema judicial contribuyó al proceso de legalidad ${ }^{55}$, pues permitió su operatividad en diversos ámbitos.

de centralizar el poder y monopolizar la violencia en los territorios donde ejercía soberanía fue un signo claro de debilidad: Miguel Ángel centeno, "The centre did not hold: war in Latin America and the monopolisation of violence", en Studies in the formation of de natio state in Latin America, James Dukerley Ed. (London: University of London, Institute of Latin American Studies, 2002), 54-76. No obstante, en los últimos años dicha tesis de claro corte weberiano ha empezado a ser cuestionada, en tanto los noveles Estados latinoamericanos tuvieron que enfrentar un contexto político complejo, donde la concepción pluralista de la soberanía, frecuentemente cuestionó su legitimidad y debió enfrentar constantemente rivalidades internas. Marta Irurozqui, Ciudadanos armados de ley..., 27-28.

55 Dicha noción alude a las dinámicas, intercambios y actualizaciones que los hombres hacen de las representaciones, prácticas institucionales e intervenciones sociales que recurren tanto en la creación de la ley, como a la forma de aplicarla. Remite a la noción de cultura jurídica, que permite "[...] comprender las leyes como productos culturales, pero a su vez, también como generadores de dinámicas y procesos sociales y políticos". La noción subraya el vínculo existente entre legalidad y sociedad, que hacen relevantes los procesos de institucionalización del Estado, ya que todo marco normativo interviene y modifica el entramado social, pues crea sujetos e identidades objetos de intervención. Pero, simultáneamente, la sociedad interpreta, modifica, negocia e infringe la ley. Miriam Galante, Marta Irurozqui, María E. Argeri. La razón de la fuerza .., 15-16. 
En esta misma reflexión se aplica a la administración de correos, ya que para su consolidación necesitó del apoyo de las autoridades provinciales, que en muchos casos se cristalizó en escoltas militares, como lo señaló el secretario de Hacienda Francisco Soto el 12 de septiembre de $1832^{56}$. Este hecho nos indica un fenómeno muchas veces desapercibido por parte de los investigadores del Estado, que sus organizaciones no nacen definidas, sino que son contingentes e históricas, y su desenvolvimiento obedece a múltiples factores que coadyuvan para su despliegue e institucionalidad o para su minimización y desinstitucionalización.

La erradicación de cultivos clandestinos de tabaco, en las inmediaciones de Caloto y Sopinga, al sur y al norte del valle geográfico del río Cauca, respectivamente, tampoco fue un éxito, aquellas sociedades rurales siguieron cultivando la hoja, hasta que finalmente el Estado a mediados de siglo XIX, optó por liberalizar su cultivo y comercio. Pero su accionar con toda la violencia anexa, también sugiere otro proceso de la estatalidad, que busca imponer su racionalidad sobre territorialidades donde las prácticas culturales y formas de organización social son consideradas nocivas a los ideales de la ciudadanía republicana, que hacen necesaria su erradicación.

De hecho, su despliegue en aquellas márgenes del Estado expresan uno de los procesos propios de la estatalización, la promoción pero a su vez la inhibición de identidades ${ }^{57}$. En esta línea expositiva, las armas republicanas se concibieron como un espacio para reeducar a aquellos hombres cuyos

56 Carta del Secretario de Estado en el despacho de hacienda al señor gobernador de Popayán, Bogotá 12 de septiembre de 1832, en: ACC. AM. 1832. Paquete 21, legajo 9.

57 María E. Argeri, "Violencia y legitimidades políticas. Norpatagonia 1880-1930", en La razón de la fuerza, 149-196. La autora afirma que después de la conquista del desierto en la Patagonia, ciertas prácticas de los grupos étnicos como el malón (acciones rápidas de asalto a poblaciones y fuertes) fueron resignificadas desde la perspectiva penal y policial del Estado, pasando a ser actos criminales, sentido que hasta ese momento no había tenido. Igualmente, como lo señala Carmen Mc Evoy, para el Perú del siglo XIX, la República, constituyó “ “... una ideología moralizadora, disciplinadora y generadora de identidades colectivas. De esta manera el Estado promovió un tipo de identidad, pero a su vez negando o inhibiendo otras que pasaban por las antiguas formas corporativas hispánicas. Carmen Mc Evoy, La utopía republicana. Ideales y realidades en la formación de la cultura política peruana (1871-1919) (Lima: Fondo Editorial Pontificia Universidad Católica del Perú, $2^{a}$ edición, 2017), 50. Sobre la forma como el Estado promueve e inhibe identidades: Philip Corrigan y Derek Sayer, "El Gran Arco. La formación del Estado, 45. 
comportamientos díscolos eran una carga para la sociedad (me refiero al reclutamiento de los vagos y mal entretenidos). Además, por medio del enrolamiento en la guardia nacional por parte de los vecinos de los distritos parroquiales, se buscaba promover los ideales republicanos. De esta manera, se exaltaba un tipo de identidad del vecino comprometido con el bien público y se anatemizaba a todos aquellos considerados una carga para la sociedad. Dichos planteamientos se llevaron a la máxima expresión en la región durante el régimen liberal de mediados de siglo, por medio del enrolamiento de los miembros de las sociedades democráticas en las milicia ${ }^{58}$.

Al respecto, para citar un ejemplo por fuera de las territorialidades aludidas, en una carta fechada desde el Trapiche el 9 de agosto de 1834, enviada al gobernador de la provincia, por el teniente Mariano Guevara, se refirió a un sitio de colonización del hoy denominado alto Putumayo, de esta manera:

Señor habiendo venido a este pueblo en asunto de comercio, entre ellos he encontrado uno de los que no puede llamarse pueblo, sino depósito de bandidos, pues se compone de reos prófugos, esclavos huidos de sus amos y de hombres desconocidos que podrán ser y son perjudiciales a todos los vecinos de este cantón y en un día al gobierno mismo. [...] En esta virtud, Vuestra Señoría debe tomar las providencias más necesarias para contener semejantes abusos, expidiendo si es conveniente la orden necesaria a los jueces y jefes militares para que se arme una partida de cincuenta o más hombres, bajo la dirección del comandante Romualdo López y yo, que me comprometo a ir con la orden de V. S. en obsequio de la patria y el bien $\mathrm{g}(\mathrm{ene})$ ral de los pueblos, como buen ciudadano. Con este motivo me suscribo de VS muy atento servidor. Q. S. M. R. Teniente Mariano Guevara ${ }^{59}$.

58 James Sanders, Contentious Republicans. Popular politics, race and class in nineteenth - Century Colombia. (Duke University Press, 2004), 65-70.

59 ACC. AM. 1834, Paquete 24, legajo 8, carta fechada en el Trapiche, 9 de agosto de 1834. La negrilla es mía (ortografía ha sido corregida del original). 
Más allá de los intereses del oficial Guevara de promover una campaña militar sobre el sitio de Escancé, su misiva expresó una visión más o menos compartida por las autoridades respecto a los asentamientos que se distanciaban del ideal de vida que el Estado republicano promovía.

\section{Conclusiones}

Los procesos de construcción del Estado no son lineales o vectoriales, en la marcha, diversos factores se conjugan para desplegar su institucionalidad o para replegarla. El presente escrito privilegió las actividades que las diversas unidades armadas republicanas ejercieron en las provincias del Cauca, para evidenciar la importancia que tuvieron en hacer más tangible el ejercicio de gobierno de los diversos poderes públicos que desde los años treinta hicieron presencia en el territorio.

Si bien el Estado ideal -en referencia a los modelos anglosajones o franceses- que durante muchos años los investigadores no encontraron en nuestro contexto, dio pie para argumentar la tesis de su inexistencia o fracaso del mismo, o para señalar con base en la teoría de la dependencia, de ser una suerte de oficina al servicio de intereses imperiales atlánticos, hoy no tiene cabida. El Estado que se construyó en las primeras décadas de vida independiente, se hizo con los materiales y herramientas disponibles por parte de los diversos grupos de poder en pugna (nunca hegemónicos), para fundar una institucionalidad sobre los códigos y normas republicanas. En este ejercicio, requirieron del apoyo de sus cuerpos armados, con los cuales buscaron hacer presencia en diversas territorialidades, a partir de actividades de policía y control social, como también de disuasión y violencia.

Las acciones desplegadas por las unidades regulares o de milicias en las provincias del Cauca, fue protagónica para dar soporte a las burocracias incipientes que con la precariedad fiscal, intentaron construir un nuevo orden político, que en muchos casos se yuxtapuso a las normas de antiguo régimen, pero buscando siempre implementar los códigos republicanos, sobre una sociedad aún modelada por las estructuras corporativas de viejo cuño. 


\section{Bibliografía}

\section{Fuentes primarias}

Archivo Central del Cauca (ACC). Fondo Archivo Muerto (AM).

ACC. AM. 1832. Paquete 21, legajo 9; ACC. AM. 1833. Paquete 23, legajo 2, 13, 15, 25, 32; ACC. AM. 1834. Paquete 24, legajo 8, 25, 27, 41; ACC. AM. 1835. Paquete 25, legajo 24, 29, 53; ACC. AM. 1836. Paquete 26, legajo 35, 36, 41; ACC. AM. 1837. Paquete 27, legajo 8, 36, 38; ACC. AM. 1839. Paquete 29, legajo 21, 45; ACC. AM. 1840. Paquete 30, legajo 39; ACC. AM. 1840. Paquete 31, legajo 47; ACC. AM. 1841. Paquete 32, legajo 56; ACC. AM. 1841. Paquete 33, legajo 62, 63, 73; ACC. AM. 1841. Paquete 32, legajo 56; ACC. AM. 1842. Paquete 35, legajo 4, 42, 43, 44, 47; ACC. AM. 1843. Paquete 36, legajo 18, 26, 27, 47, 69; ACC. AM. 1843. Paquete 37, legajo 70, 74, 77; ACC. AM. 1843. Documentos de diversas comandancias del ramo militar; ACC. AM. 1843. Documentos de diversas comandancias del ramo militar, Bis; ACC. AM: 1843. Diversos documentos del batallón Neira No 3º ACC. AM. 1844. Paquete 38, legajo 5, 48; ACC. AM. 1846. Paquete 40, legajo 47, 65; ACC. AM. 1846. Paquete 41, legajo 75 bis, 80, 82; ACC. AM. 1847. Paquete 43, legajo 82, 83, 85; ACC. AM. 1848. Paquete 44, legajo 2; ACC. AM. 1848. Paquete 45, legajo 67 bis., 69, 70; ACC. AM. 1849. Paquete 46, legajo 48; ACC. AM. 1849. Paquete 47, legajo 73, 75, 84; ACC. AM. 1850. Paquete 49, legajo 69, 84, 76, 81, 84; ACC. AM. 1851. Paquete 50, legajo 50; ACC. AM. 1851. Paquete 51, legajo 57, 58, 67; ACC. AM. 1852. Paquete 52, legajo 41; ACC. 1843, Criminal, signatura 1841; ACC. AM. 1851. Comunicaciones gobernación de Túquerres (varios documentos); ACC. AM. 1851. Documentos de las gobernaciones de las provincias de Popayán, Cauca y Pasto.

\section{Fuentes primarias impresas}

Codificación Nacional de todas las leyes de Colombia, Tomo 9, (Bogotá: Imprenta Nacional, 1927).

174 Informe del secretario de Estado en el despacho de Guerra de la Nueva Granada al Congreso constitucional de 1851 (Bogotá: Imprenta del Neo-Granadino, por León Echevarría, 1851). 
Informe del secretario de Estado del despacho de Guerra de la Nueva Granada al Congreso constitucional de 1853 (Bogotá: Imprenta Neogranadino, 1853).

\section{Fuentes secundarias citadas en el artículo}

Aguirre, Carlos y Walker, Charles, Comp., Bandoleros, abigeos y montoneros. Criminalidad y violencia en el Perú, siglos XVIII-XX, Lima: Instituto de Apoyo Agrario, 1990.

Archer, Christon I. "To Serve the King: Military Recruitment in Late Colonial Mexico", The Hispanic American Historical Review, Vol. 55, No. 2 (1975), 226-250.

Argeri, María E. De guerreros a delincuentes. La desarticulación de las jefaturas indígenas y el poder judicial. Norpatagonia, 1880-1930, Madrid: Consejo Superior de Investigaciones Científicas, 2005.

Castellanos, Jorge. La abolición de la esclavitud en Popayán, 1832-1852, Cali: Universidad del Valle, 1980.

Centeno, Miguel Ángel. Sangre y Deuda. Ciudades, Estado y construcción de Nación en América Latina, Bogotá: Universidad Nacional, 2014.

Centeno, Miguel Ángel. "The centre did not hold: war in Latin America and the monopolisation of violence", en Studies in the formation of de natio state in Latin America, Ed. James Dukerley, London: University of London, Institute of Latin American Studies, 2002.

Corrigan, Philip y Sayer, Derek. "El Gran Arco. La formación del estado inglés como revolución cultural”, en María L. Lagos y Pamela Calla, Comps., Antropología de Estado. Dominación y prácticas contestarías en América Latina, (La Paz: INDH/PNUD, 2007), 39-116.

Das, Veena y Poole, Deborah. "El Estado en las márgenes. Etnografías comparadas", Cuadernos de Antropología Social, No. 27, (2008).

Díaz, María Camila. Salteadores y cuadrillas de malhechores. Una aproximación a la acción colectiva de la "población negra" en el suroccidente de la Nueva Granada, 1840-1851, Popayán: Editorial Universidad del Cauca, 2015.

Falcón, Romana y Buve, Raymon, Coord. Pueblos en tiempos de Guerra. La formación de la nación en México, Argentina y Brasil (18001920), México: El Colegio de México, 2017. 
Fradkin, Raúl O. "Bandolerismo y politización de la población rural de Buenos Aires tras la crisis de la independencia (1815-1830)", Nuevo mundo mundos nuevos, No 5 (2005), disponible: http://nuevomundo.revues.org/document309.html.

Fradkin, Raúl O. y Ratto, Silvia. "Desertores, bandidos e indios en la frontera de Buenos Aires, 1815-1819”, Secuencia, No 74, (2009), 11-41.

Galante, Miriam; Irurozqui Victoriano, Marta y Argeri, María E. La razón de la fuerza y el fomento del derecho. Conflictos jurisdiccionales, ciudadanía y mediación estatal (Tlaxcala, Bolivia y Norpatagonia), Madrid: Consejo Superior de Investigaciones Científicas, 2011.

Garavaglia, Juan Carlos. "Ejército y milicia: Los campesinos bonaerenses y el peso de las exigencias militares, 1810-1860", Anuario IEHS, No 18 (2003), 153-187.

Garavaglia, Juan Carlos. La disputa por la construcción nacional Argentina. Buenos Aires, la Confederación y las provincias (1850-1865), Buenos Aires: Prometeo Editores, 2015.

Hobsbawm, Eric. Bandidos, Barcelona: Crítica Editorial, 2011.

Hobsbawm, Eric. Rebeldes Primitivos. Estudio sobre las formas arcaicas de los movimientos sociales en los siglos XIX y XX, Barcelona: Editorial Ariel, 1983.

Irurozqui, Marta. Ciudadanos armados de ley. A propósito de la violencia en Bolivia, 1830-1875, La Paz: Instituto Francés de Estudios Andinos, Ediciones Plural, 2018.

Joseph, Gilbert M. "On the Trail of Latin American Bandits: A reexamination of peasant resistance", Latin American Research Review, Vol. 25, No. 3 (1990), 7-53.

Loveman, Brian. For la Patria. Politics and the Armed Forces in Latin American, Wilmington: Scholary Resources Inc, 1999.

Macías, Flavia. "El deber de enrolarse y el derecho a votar: reflexiones en torno a la ciudadanía armada y el sufragio en Argentina, 1863-1877”, Revista de Indias, Vol. LXXVI, No. 266, (2016), 233-258.

Macías, Flavia. "Milicias, levantamientos armados y construcción republicana en Hispanoamérica. Estudios y propuestas para el siglo XIX", Boletín del Instituto de Historia de Argentina "Dr. Emilio Ravignani”, No 42 (2015), 24-30. 
Macías, Flavia. Armas y Política en Argentina. Tucumán, siglo XIX, Madrid: Consejo Superior de Investigaciones Científicas, 2014.

Macías, Flavia y Sábato, Hilda. "La Guardia Nacional: Estado, política y uso de la fuerza en la Argentina de la segunda mitad del siglo XIX", Revista PolHis, Vol. 6, No 11 (2013), 70-81.

McEvoy, Carmen y Rabinovich, Alejandro. Eds. Tiempo de guerra. Estado, nación, y conflicto armado en el Perú, siglo XVII-XIX, Lima: Instituto de Estudios Peruano, 2018.

Mc Evoy, Carmen. La Utopía republicana. Ideales y realidades en la formación de la cultura política peruana (1871-1919), Lima: Fondo Editorial Pontificia Universidad Católica del Perú, 2a edición, 2017.

Méndez, Cecilia. La República plebeya. Huanta y la formación del Estado peruano, 1820-1850, Lima: Instituto de Estudios Peruanos, 2014.

Nunn, Frederick M. "Latin American Military-Civilian from independence to the present. A course conspectus", History teacher, Vol. 14, No 3 (1981), 423-437.

Maingot, Anthony P. "Social structure, social status and civil-military conflict in urban Colombia, 1810-1851", Nineteenth Century Cities. Essays in the new urban History, Stephan Thernstrom, Richard Sennett Edit. New Haven: Yale University Press, 1969, 296-355.

Pacheco, Margarita Rosa. La fiesta liberal en Cali. Cali: Universidad del Valle, 1992.

Pérez Villa, Ángela. "Disorderly Love: Illicit Friendships, Violence, and Law in a Slave Society at War, Popayán-Colombia, 1809-1830”, A dissertation submitted in partial fulfillment of the requirements for the degree of Doctor of Philosophy, University of Michigan, 2017.

Perlmutter, Amos. "The Praetorian State and the Praetorian Army: Toward a Taxonomy of Civil-MilitaryRelations in Developing Polities", Comparative Politics, Vol. 1, No. 3 (1969), 382-404.

Prado Arellano, Luis Ervin. "La organización de los ejércitos republicanos en la Nueva Granada: Provincias del Cauca (1830-1855)”, Tesis doctoral en Historia Latinoamericana, Universidad Andina Simón Bolívar, Ecuador, 2019.

Prado Arellano, Luis Ervin. "Ecuador y la guerra civil de los Supremos en los Andes surcolombianos (1839-1842), Anuario de Historia Regional y de las Fronteras, Vol. 6 (2001), 65-86. 
Prado Arellano, Luis Ervin; Prado Valencia, David y Ramírez Tobar Laura Helena. Diarios de las guerras de mediados de siglo en las provincias del Cauca, 1851-1854, Popayán: Editorial Universidad del Cauca, 2014.

Sanders, James. Contentious Republicans. Popular politics, race and class in nineteenth - Century Colombia, Duke University Press, 2004.

Slatta, Richard W. "Bandits and rural social history: A comment on Joseph", Latin American Research Review, Vol. 26, No 1 (1991), 145151.

Sierra, Luis F. El tabaco en la economía colombiana del siglo XIX, Bogotá: Universidad Nacional de Colombia, 1971.

Soprano, Germán. "La profesión militar en los estudios sobre fuerzas armadas y sociedad. Lecturas, interpretaciones, y usos desde la argentina actual", Cuadernos de Marte, Vol. 4, No. 5 (2013), 63-97.

Valencia Llano, Alonso. Dentro de la ley. Fuera de la ley. Insurgencia social en el valle del Cauca, 1810-1854, Cali: Universidad del Valle, $2^{\mathrm{a}}$ edición, 2016.

Vanderwood, Paul J. Los rurales mexicanos, México: Fondo de Cultura Económica, 2012.

Para citar este artículo: Prado Arellano, Luis Ervin. "Desplegando el Estado: los ejércitos republicanos en las provincias del Cauca, 1832-1855", Historia Caribe Vol. XIV No. 35 (Julio-Diciembre 2019): 149-178. DOI: http://dx.doi.org/10.15648/hc.35.2019.6 